\title{
Real Imager 8
}

National Cancer Institute

\section{Source}

National Cancer Institute. Real Imager 8. NCI Thesaurus. Code C142871.

A proprietary imaging system designed to determine breast health through the acquisition and analysis of 3D imaging biomarkers. It provides a radiation-free complement for mammography particularly suited for women with dense breast tissue. 